\title{
Comparison of ex vivo expansion culture conditions of mesenchymal stem cells for human cell therapy
}

\author{
Maitane Pérez-Ilzarbe,* María Díez-Campelo,* Pablo Aranda, Soraya Tabera, Tania Lopez, \\ Consuelo del Cañizo, Juana Merino, Cristina Moreno, Enrique J. Andreu, Felipe Prósper, and \\ José Antonio Pérez-Simón
}

BACKGROUND: Mesenchymal stem cells (MSCs) are multipotent stem cells. Based on their properties, several clinical trials have been designed to explore their potential therapeutic effect. Fetal calf serum (FCS, commonly used for in vitro expansion) is an undesirable source of xenogeneic antigens and bears the risk of transmitting contaminations. As an alternative for FCS, platelet lysate $(\mathrm{PL})$ and both autologous and allogeneic human serum have been proposed. The aim of this study is to compare the culture of bone marrow (BM)derived MSCs in the presence of different serum supplements to determine the effect on cell growth, differentiation potential, and immunologic function. STUDY DESIGN AND METHODS: MSCs from BM of healthy volunteer donors were grown in the presence of $10 \%$ FCS supplemented with $1 \mathrm{ng} / \mathrm{mL}$ basic fibroblast growth factor (bFGF), 10\% human serum supplemented with $1 \mathrm{ng} / \mathrm{mL}$ bFGF, 5\% PL, and PL 5\% supplemented with $1 \mathrm{ng} / \mathrm{mL}$ bFGF (PL plus bFGF).

RESULTS: MSCs that expanded in either medium showed a comparable morphology, phenotype, and proliferative and differentiation capacity. While the presence of MSCs in vitro significantly decreased CD3/ CD28-mediated T-cell activation, this effect was significantly higher in MSCs cultured with human serum. Production of interferon- $\gamma$ was inhibited by cocultured media with MSCs while MSCs also induced a significant inhibition of cell cycle in T cells.

DISCUSSION: In conclusion, PL or autologous serum could offer an alternative to the use of FCS in MSC expansion for clinical use maintaining the same growing potential, phenotype, immunomodulatory properties, and differentiation potential.

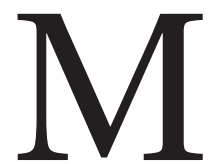

esenchymal stem cells (MSCs) are multipotent stem cells that can be recovered/ obtained from a variety of tissues such as bone marrow (BM), cord blood, adipose tissue, amniotic fluid, and so forth. ${ }^{1-3}$ MSCs are plastic adherent in standard culture conditions. ${ }^{4}$ Phenotypically, they express a number of nonspecific markers such as CD105, CD73, and CD90; lack expression of hematopoietic markers such as CD45, CD34, CD14 or CD11b, CD79 $\alpha$ or CD19, and HLA-DR;,6 and can differentiate into osteoblasts, adipocytes, and chondrocytes. ${ }^{7}$ Based on their immunomodulatory and regenerative properties, several

ABBREVIATIONS: APC = allophycocyanin; $\mathrm{bFGF}=$ basic fibroblast growth factor; $\mathrm{BM}=$ bone marrow; $\mathrm{MFC}=$ mean fluorescence channel; $\operatorname{MSC}(\mathrm{s})=$ mesenchymal stem cell(s); pen/strep $=$ penicillin $/$ streptomycin; PerCP $=$ peridinin chlorophyll protein; $\mathrm{PL}=$ platelet lysate; $\mathrm{PMA}=$ phorbol myristate acetate.

From the Hematology, Cell Therapy Area and Immunology Service, Clínica Universitaria, Universidad de Navarra, Pamplona; the Department of Hematology, Hospital Clínico Universitario de Salamanca, Salamanca; and the Centro de Medicina Regenerativa y Terapia Celular de Castilla y Leon, Castilla y Leon, Spain.

Address reprint requests to: Felipe Prosper, Hematology and Cell Therapy, Clínica Universitaria, Avda. Pío XII 36, Pamplona 31008, Spain. e-mail: fprosper@unav.es.

*MPI and MDC contributed equally to the manuscript.

Supported in part by grants from Fondo de Investigaciones Sanitarias ISCIII-RETIC RD06/0014, Caja de Ahorros de Navarra (Programa Tu Eliges: Tu Decides), and the "UTE project CIMA" to FP and ISCII (Convenio de Terapias Avanzadas). MDC was supported by a grant from Fondo de Investigaciones Sanitarias (ISCIII-CM05/00107.9).

Received for publication October 31, 2008; revision received March 9, 2009, and accepted March 10, 2009.

doi: 10.1111/j.1537-2995.2009.02226.x

TRANSFUSION **;*******. 
clinical trials have been designed in an attempt to explore their therapeutic potential in graft-versus-host disease (GVHD), Chron disease, multiple sclerosis, diabetes, myocardial infarction, cirrhosis, and osteogenesis imperfecta (http://www.clinicaltrials.gov).

Remarkably, most clinical trials use BM-derived MSCs (BM-MSCs) generated in a medium supplemented with fetal calf serum (FCS). However, FCS is an undesirable source of xenogeneic antigens and bears the risk of transmitting animal viral, prion, and zoonose contaminations. As an alternative for FCS, platelet lysate (PL) $)^{8-12}$ and both autologous and allogeneic human serum have been proposed. ${ }^{13-15}$ The use of allogeneic human serum has resulted in MSC growth arrest and death in some studies while the use of autologous serum allows a faster proliferation compared to FSC at least during the first passages and, in addition, avoids the exposure to allogeneic antigens and minimizes the risk of infection. ${ }^{13,15-17}$ Nevertheless, the amount of autologous serum required for a sufficient expansion exceeds the amount a donor could provide. We have previously reported a method for obtaining large amounts of autologous serum for in vitro culture of human skeletal myoblasts at a clinical scale. ${ }^{18}$

The aim of this study is to compare culture medium supplemented with FCS with alternative supplements such as human serum and PL. We compared the effects of different types of media on the yield of MSC cultures, proliferation, and differentiation capacity as well as on their immunologic properties.

\section{MATERIALS AND METHODS}

\section{Isolation and culture of BM mononuclear cells}

Human MSCs were isolated from the BM of healthy volunteer donors after informed consent was obtained, according to the local Ethics Committee at University of Navarra. A total of 30 to $40 \mathrm{~mL}$ of BM was obtained by multiple 2- to 3-mL aspirations from the iliac crest under local anesthesia, according to standard institutional procedures. The median age of BM donors was 20 years (range, 19-21 years).

Mononuclear cells (MNCs) were isolated by a density gradient centrifugation (Ficoll-Paque, GE Healthcare BioSciences, AB, Uppsala, Sweden). Briefly, 2 vol of BM was added to $1 \mathrm{vol}$ of Ficoll in a tube and centrifuged at $800 \times g$ for 20 minutes. MNCs were resuspended and plated in noncoated 75 - to $175-\mathrm{cm}^{2}$ polystyrene culture flasks (Corning Costar, Celbio, Milan, Italy) in modified Eagle's medium- $\alpha$ ( $\alpha$-MEM [Gibco, Invitrogen, Paisley, UK]) with $1 \%$ penicillin/streptomycin (pen/strep; Gibco) at a concentration of 115,000 cells $/ \mathrm{cm}^{2}$. Four different supplements were tested:

1. $10 \%$ FCS (BioWhittaker, Lonza, Verviers, Belgium) supplemented with $1 \mathrm{ng} / \mathrm{mL}$ basic fibroblast growth factor (bFGF; Sigma, St Louis, MO; FCS medium);

2. $10 \%$ human serum supplemented with $1 \mathrm{ng} / \mathrm{mL}$ bFGF (HS medium) obtained by venipuncture;

3. $5 \%$ PL; and

4. PL 5\% supplemented with $1 \mathrm{ng} / \mathrm{mL}$ bFGF (PL plus bFGF).

To lyse the platelets (PLTs) different PLT apheresis collections were discarded from the Blood Bank of the Clínica Universitaria de Navarra and were frozen at $-80^{\circ} \mathrm{C}$ and then thawed at $37^{\circ} \mathrm{C}$ to lysate the PLTs to obtain the released growth factors. Samples were centrifuged at $900 \times g$ for 30 minutes to discard PLTs. Supernatant was used as a supplement and $10 \mathrm{IU}$ of heparin per $5 \mathrm{~mL}$ of medium was added before use to avoid gel formation. Cells were incubated in a humidified atmosphere with complete medium replacement twice a week. The first passage (P1) was performed when cells reached a confluence of $70 \%$ to $80 \%$ (Days 10-15). MSCs were then replated at a concentration of 1000 to 5000 cells $/ \mathrm{cm}^{2}$ and passaged when a confluence of $80 \%$ was reached (P2-P4). The number of cells and the duplication time was calculated after P1 to P4.

\section{Characterization of MSCs}

\section{Immunophenotype}

For fluorescence-activated cell sorter (FACS) analysis, the following antibodies were used: CD34-allophycocyanin (APC), CD44-fluorescein isothiocyanate (FITC), CD45peridinin chlorophyll protein (PerCP), CD73phycoerythrin (PE), and CD90-FITC (all from BD PharMingen, San Diego, CA) and their corresponding isotype controls (all from BD PharMingen). A total of 50,000 to 200,000 cells were incubated with primary antibody for 15 minutes in the dark at room temperature. Cells were fixed with $4 \%$ formaldehyde at $4^{\circ} \mathrm{C}$. The analysis was performed on a flow cytometer (FACSCalibur, Becton Dickinson Biosciences, San Jose, CA). Calibration of the instrument was performed before data acquisition using previously well-established protocols. ${ }^{9}$ A software program (CellQuest, Becton Dickinson Biosciences) was used for the acquisition of 50,000 total cells. Data analysis was performed using a computer program (Paint-A-Gate, Becton Dickinson).

\section{T-lymphocyte inhibition assay}

MSCs expanded as previously specified and were cultured in 48-well plates with $\mathrm{T}$ lymphocytes obtained from healthy donors' buffy coats by density gradient centrifugation, in a 1:10 (MSC : T-cell) ratio. Cells were cultured with $500 \mu \mathrm{L}$ per well of RPMI 1640 supplemented with $2 \mathrm{mmol} / \mathrm{L}$ L-glutamine, $100 \mathrm{U} / \mathrm{mL}$ penicillin, $100 \mu \mathrm{g} / \mathrm{mL}$ streptomycin (Gibco, Grand Island, NY) and 10\% human $\mathrm{AB}$ serum (Sigma). For activation assays we cultured $3 \times 10^{4}$ 
MSCs per well, and after 6 hours of adherence, $3 \times 10^{5} \mathrm{~T}$ cells were added. Three different conditions were analyzed: 1) baseline (unstimulated T cells); 2) brefeldin treated ( $6 \mathrm{hr}$ before acquisition in the cytometer), plus phorbol myristate acetate (PMA) and ionomycin ( $4 \mathrm{hr}$ before acquisition); and 3) T cells stimulated with plate-bound antiCD3 $(10 \mu \mathrm{g} / \mathrm{mL})$ and soluble anti-CD28 $(1 \mu \mathrm{g} / \mathrm{mL})$ monoclonal antibodies (MoAbs; BD Biosciences). After 2 days of coculture, CD4+ T cells were analyzed by flow cytometry after staining with the following combination of MoAbs: CD25-FITC/interferon (IFN) $-\gamma$-PE/CD4-PerCPCy5.5/CD40L-APC. For intracytoplasmic staining of IFN- $\gamma$ and CD40L, a fixation and permeabilization stain kit (IntraStain, Dako Cytomation, Glostrup, Denmark) was used following the manufacturer's instructions.

For proliferation assays we cultured $5 \times 10^{4}$ MSCs per well, and after 6 hours of adherence, $5 \times 10^{5} \mathrm{~T}$ cells per well were added. Two different conditions were used for this analysis: 4) baseline (unstimulated T-cells) and 5) T cells stimulated with plate-bound anti-CD3 $(10 \mu \mathrm{g} / \mathrm{mL})$ and soluble anti-CD28 $(1 \mu \mathrm{g} / \mathrm{mL})$ MoAbs (BD Biosciences). After 5 days of coculture, two studies were performed: cell cycle analysis and PKH staining analysis. Cell cycle analysis with propidium iodide (PI) staining was performed by flow cytometry after staining with $\mathrm{CD} 2 / \mathrm{CD} 3 / \mathrm{CD} 5 /$ CD7-FITC/PIPerCP-Cy5.5. For PI staining, a DNA reagent kit (CycleTest Plus, Becton Dickinson, Erembodegem, Belgium) was used following the manufacturer's instructions. T cells were stained with PKH-67 on Day 0 and stimulated with plate-bound anti-CD3 $(10 \mu \mathrm{g} / \mathrm{mL})$ and soluble anti-CD28 $(1 \mu \mathrm{g} / \mathrm{mL})$ MoAbs. T cells cultured for 5 days (whether or not in the presence of MSCs) were collected; stained with CD25-PE, 7-aminoactinomycin, and CD3APC MoAbs; and analyzed by flow cytometry.

Paint-A-Gate software was used to calculate the percentage and mean fluorescence channel (MFC) of activated T-Ly (positive cells for CD25, IFN- $\gamma$, and CD40L); ModFit software was also used to calculate the percentage of resting and proliferating $T$ cells in the cell cycle analysis. Paint-A-Gate software was used to calculate the percentage of proliferating activated $\mathrm{T}$ cells $\left(\mathrm{PKH}^{\mathrm{dim}} \mathrm{CD} 25+\right)$, nondivided activated $\mathrm{T}$ cells ( $\left.\mathrm{PKH}^{\text {high }} \mathrm{CD} 25+\right)$, and nonactivated $\mathrm{T}$ cells ( $\left.\mathrm{PKH}^{\text {high }} \mathrm{CD} 25-\right)$ among viable T cells. ModFit software was also used to calculate the percentage of resting and proliferating cells.

\section{Differentiation assays}

To induce osteogenic differentiation, cells were replated at $6000 \mathrm{cells} / \mathrm{cm}^{2}$ and cultured for 3 weeks in $\alpha$-MEM with $10 \mathrm{mmol} / \mathrm{L} \beta$-glycerophosphate (Sigma), $0.2 \mathrm{mmol} / \mathrm{L}$ ascorbic acid (Sigma), $0.1 \mu \mathrm{mol} / \mathrm{L}$ dexamethasone (Sigma), 10\% FCS (Biochrom, Berlin, Germany), and 1\% pen/strep. After 21 days cells were analyzed by alkaline phosphatase and alizarin red staining. Adipogenic differentiation was induced by culturing confluent MSCs in
$\alpha$-MEM with $50 \mu \mathrm{mol} / \mathrm{L}$ indomethacin (Sigma), $0.5 \mathrm{mmol} / \mathrm{L}$ isobutyl-methylxanthine (Sigma), $1 \mu \mathrm{mol} / \mathrm{L}$ dexamethasone (Sigma), 10\% FCS, and 1\% pen/strep for 21 days. Oil Red-O staining was performed to identify the adipocyte cells. To induce condrogenic differentiation, $2 \times 10^{5}$ cells were placed in a $15-\mathrm{mL}$ conical tube to allow aggregation of the cells in a micromass suspension culture and kept for 21 days in DMEM-HG (DMEM with $4 \mathrm{~g} / \mathrm{L}$ glucose; Gibco) supplemented with $1 \%$ universal culture supplement (ITS+ Premix, BD Biosciences; consisting of $6.25 \mu \mathrm{g} / \mathrm{mL}$ insulin, $6.25 \mu \mathrm{g} / \mathrm{mL}$ transferrin, $6.25 \mathrm{ng} / \mathrm{mL}$ selenious acid, $1.25 \mathrm{mg} / \mathrm{mL}$ serum albumin [Sigma], and $5.35 \mu \mathrm{g} / \mathrm{mL}$ linoleic acid), $100 \mu \mathrm{g} / \mathrm{mL}$ sodium pyruvate, $50 \mu \mathrm{g} / \mathrm{mL}$ ascorbate-2-phosphate, $0.1 \mu \mathrm{mol} / \mathrm{L}$ dexamethasone (Sigma), $500 \mathrm{ng} / \mathrm{mL}$ BMP6, $10 \mathrm{ng} / \mathrm{mL}$ transforming growth factor- $\beta 3$ (TGF- $\beta 3$ ), and $1 \%$ pen/strep. After 3 weeks, differentiation was analyzed by staining the micromasses with toluidine blue in $5-\mu \mathrm{m}$ sections.

\section{Statistical analysis}

Median values and ranges were calculated for each variable. To explore the significance in the differences found between the different groups a normality test was performed. Normally distributed samples were compared using the analysis of variance followed by post hoc test while a Kruskal-Wallis test was used for samples that did not fit a normal distribution. Paired-sample t tests were performed to compare the effect of MSCs on T-lymphocyte activation and proliferation within the different types of culture. Computer software (SPSS 15.0, SPSS, Inc., Chicago, IL) was used. Differences were considered to be significant when $\mathrm{p}$ values were less than 0.05 .

\section{RESULTS}

To compare the effects of the different media supplements on cell growth and characteristics of BM-MSCs, BM-derived MNCs from eight different donors were plated in parallel using four different culture conditions (see Materials and Methods). PL was obtained for a pool of at least 10 different donors and used for cultures. PLT concentration from each donor ranged between $1 \times 10^{9}$ and $2 \times 10^{9}$ per $\mathrm{mL}$. Cultures were maintained until $\mathrm{P} 4$ when they were terminated (median number of days in culture for all four conditions was $29 \pm 4$ ). Neither the number of population doublings nor the calculated cumulative number of MSCs after P4 (Table 1 and Fig. 1) were statistically different between the various culture media. The addition of bFGF to media with PL did not significantly increase the number of cells obtained in the culture. The times taken to reach both the P4 and MSC duplication period were not significantly different between the various media. Interestingly, duplication time increased 


\begin{tabular}{|c|c|c|c|c|c|c|}
\hline \multirow[b]{2}{*}{ Medium } & \multicolumn{2}{|c|}{ P1-P2 } & \multicolumn{2}{|c|}{ P2-P3 } & \multicolumn{2}{|c|}{ P3-P4 } \\
\hline & PD & DT (hr) & PD & DT (hr) & PD & DT (hr) \\
\hline Human serum & $3.95 \pm 1.64$ & $36.44 \pm 15.20$ & $6.49 \pm 2.63$ & $56.8 \pm 23.05$ & $7.69 \pm 2.9$ & $\overline{112.02 \pm 45.44 \dagger}$ \\
\hline $\mathrm{PL}+\mathrm{bFGF}$ & $4.04 \pm 1.52$ & $35.66 \pm 13.51$ & $7.18 \pm 1.49$ & $41.37 \pm 8.58$ & $8.97 \pm 2.26$ & $101.47 \pm 25.64 \dagger$ \\
\hline $\mathrm{PL}$ & $3.92 \pm 1.26$ & $36.77 \pm 11.9$ & $7.09 \pm 1.75$ & $45.39 \pm 11.23$ & $8.20 \pm 2.35$ & $129.47 \pm 37.20 \dagger$ \\
\hline FCS & $3.86 \pm 1.09$ & $37 \pm 10.44$ & $7.09 \pm 1.50$ & $45.05 \pm 9.53$ & $8.33 \pm 1.22$ & $115.60 \pm 17.06 \dagger$ \\
\hline \multicolumn{7}{|c|}{$\begin{array}{l}\text { * Values represent the mean } \pm \text { SD. } p \text { Values were not significant between the different media. } \\
\dagger p<0.05 \text { in comparison with } \mathrm{DT} \text { between } \mathrm{P} 1-\mathrm{P} 2 \text { and } \mathrm{P} 2-\mathrm{P} 3 \text {. } \\
\text { DT = duplication time (in } \mathrm{hr}) ; \mathrm{PD}=\text { population doubling (cumulative). }\end{array}$} \\
\hline
\end{tabular}

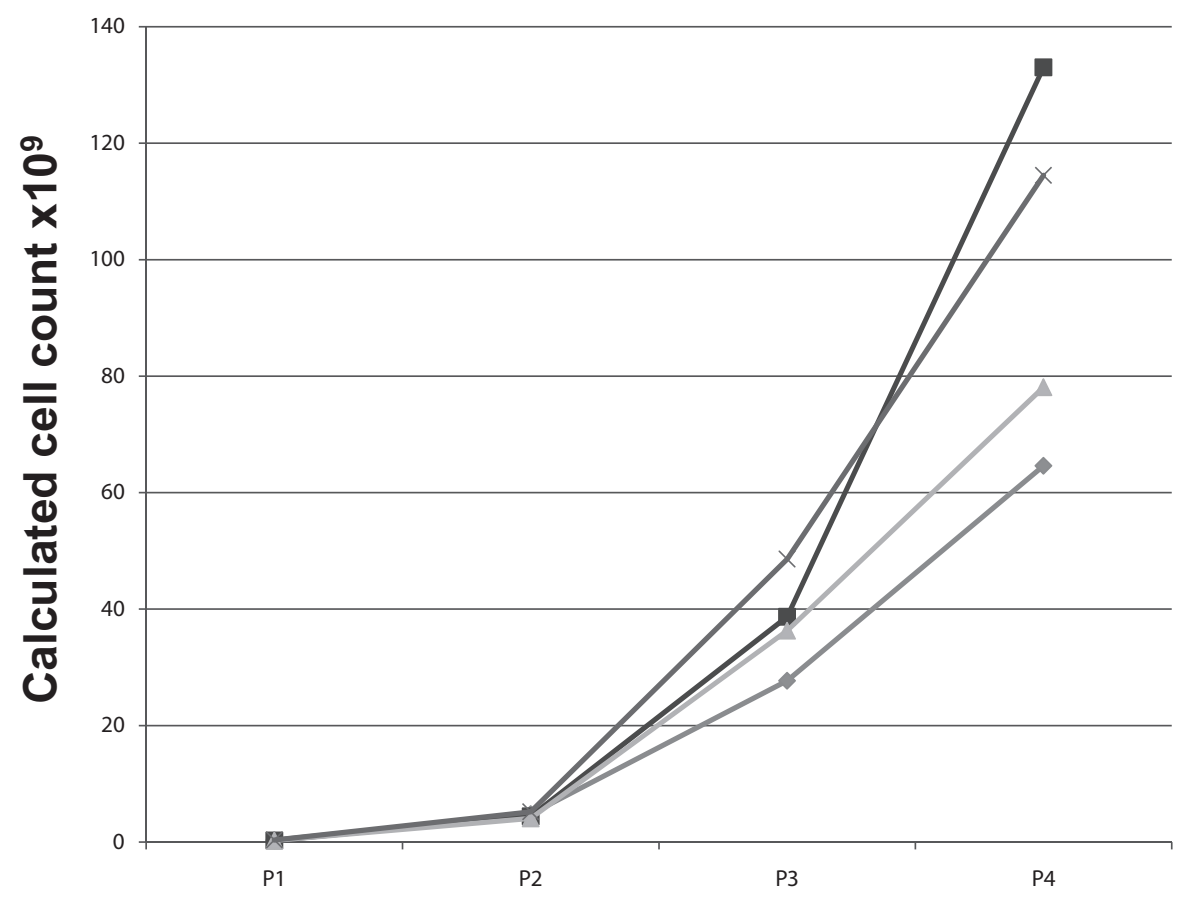

Fig. 1. Calculated cumulative cell counts of MSCs cultured from P0 to P4, in the different conditions. ( $\diamond)$ human serum; $(\Delta)$ PL; ( $\square$ ) PL + bFGF; $(\times)$ FCS. Results are expressed as the mean number of MSCs $/ 10^{7}$ plated MNC cells calculated from data obtained from eight BM donors.

throughout all cultures, being significantly longer after P3 regardless of the media used.

\section{MSC surface phenotype and differentiation capacity}

The surface phenotype of MSCs cultured under the four different conditions was analyzed by flow cytometry at P1 to $\mathrm{P} 4$; the phenotypes were similar and in agreement with previous reports. ${ }^{5,7}$ As shown in Fig. 2, MSCs were positive for CD73, CD90, and CD44 and did not express CD34 and CD45 (using the mean fluorescence intensity as criteria). Expression of CD45 was detected at P1 and P2, consistent with hematopoietic contamination that disappears after P3 (data not shown). MSCs cultured in human serum had a higher expression of CD45 and a lower expression of
CD73 and CD90 at P1, although the differences were not significant (data not shown).

Differentiation to osteogenic, adipogenic, and condrogenic cells was induced with P4 MSCs grown in the different media. As shown in Fig. 3, trilineage differentiation of MSCs was observed in all cases as determined by alkaline phosphatase activity and alzarin red, Oil Red-O, and proteoglycans staining (toluidine blue), respectively.

\section{Immunologic assays}

To confirm that MSCs expanded with human serum (HSMSC) and PL with bFGF (PL-MSC) are as good as MSCs expanded with FCS (FCS-MSC), not only in terms of expansion and cell growth but also in terms of immunosuppression properties, we performed at least five experiments coculturing MSCs and T lymphocytes under 
CD73
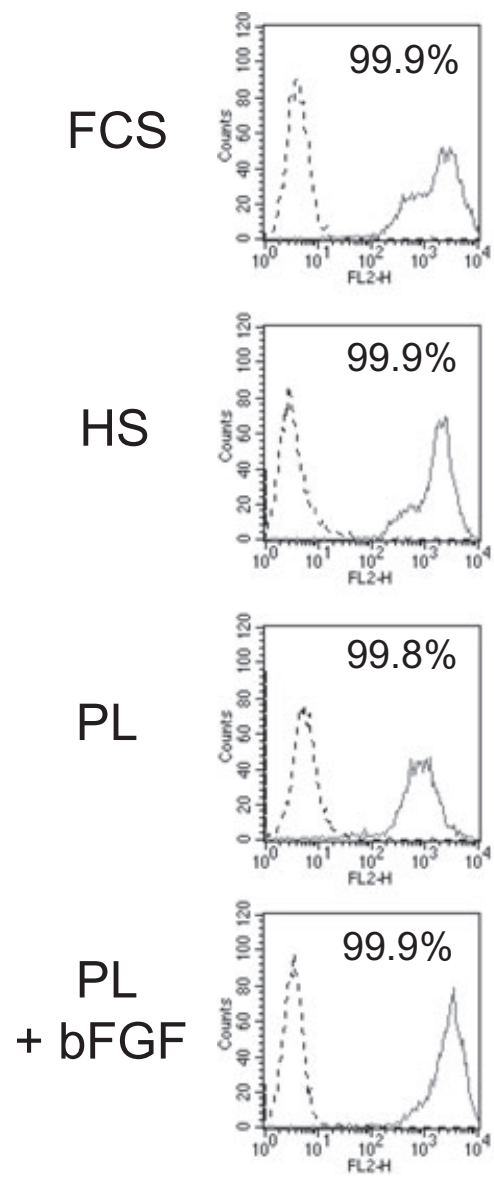

CD90
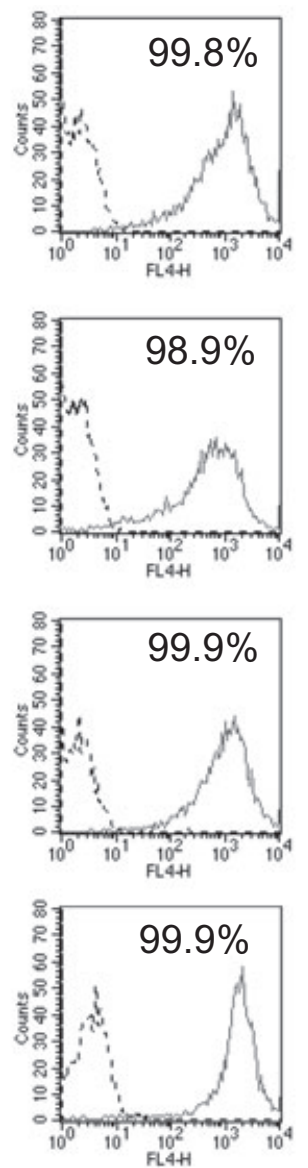

CD44
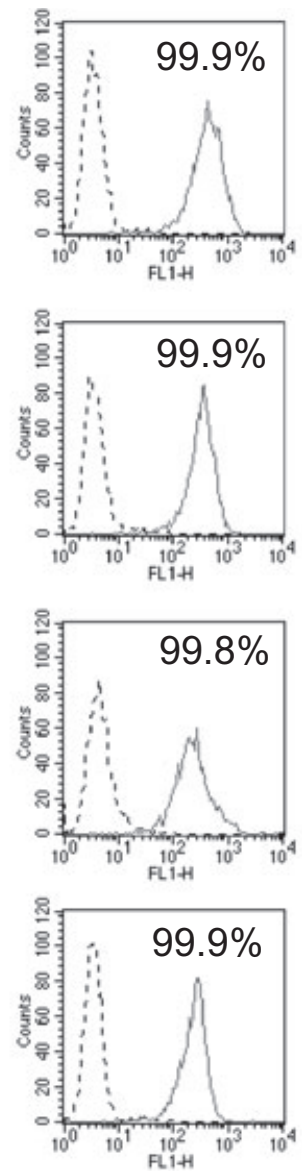

CD34
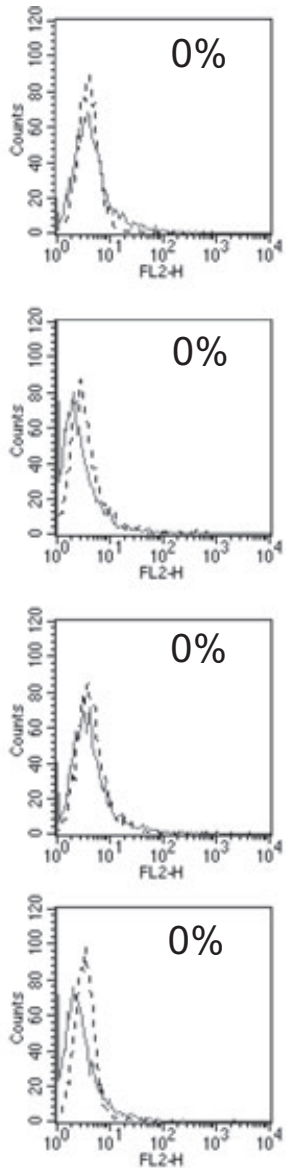

CD45
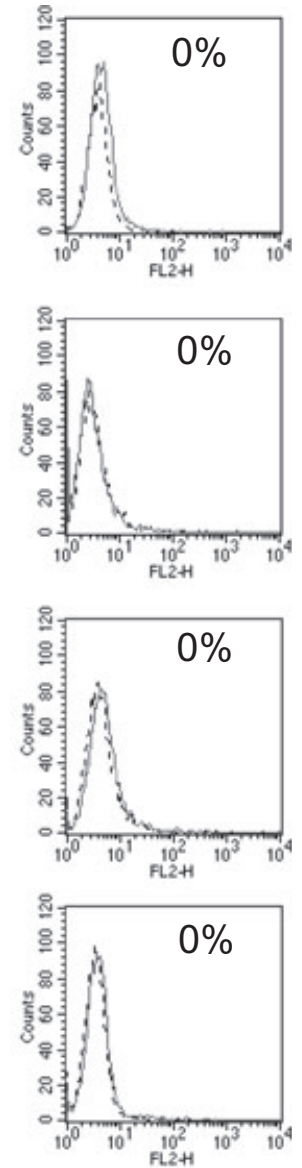

Fig. 2. FACS analysis of hMSC culture in the four different media.

different conditions (with or without stimulation of $\mathrm{T}$ cells) and analyzed the effect of MSCs on the activation pattern (measured by flow cytometry) and proliferation (evaluated by cell cycle analysis and PKH assays) of T cells.

Activation pattern in T cells (CD25, IFN- $\gamma$, and CD4OL) Among $\mathrm{T}$ cells stimulated with anti-CD3/anti-CD28, the presence of MSCs significantly influenced the expression of the activation marker CD40L. Accordingly, the expression of CD40L was significantly reduced when $\mathrm{T}$ cells were cultured with MSCs: the MFC of CD40L was 49 in T cells stimulated in the absence of MSCs (T cells alone) versus 19 in T cells plus HS-MSCs ( $p=0.015), 31$ in T cells plus FCS-MSCs $(p=0.02)$, and 24 in T cells plus PL-MSCs $(p=0.009$ ). In addition, $50 \%$ of $\mathrm{T}$ cells were CD40L positive after stimulation in the absence of MSCs compared to $17 \%$ upon coculture with HS-MSCs (T cells plus HS-MSCs; $p=0.002), 31 \%$ for $\mathrm{T}$ cells plus FCS-MSCs $(\mathrm{p}=0.004)$, and $21 \%(\mathrm{p}<0.001)$ for $\mathrm{T}$ cells plus PL-MSCs, respectively. Interestingly, HS-MSCs displayed the most intense inhibition of CD40L expression compared to PL-MSCs or FCSMSCs (Fig. 4A: the MFC of CD40L was 19 among T cells plus HS-MSCs versus 32 among T cells plus FCS-MSCs $(\mathrm{p}=0.01)$ and 26 among $\mathrm{T}$ cells plus PL-MSCs $(\mathrm{p}=0.03)$; the percentage of CD40L-positive T cells was $17 \%$ in T cells plus HS-MSCs versus $33 \%$ in T cells plus FCS-MSCs $(\mathrm{p}=0.002)$ and $23 \%$ in T cells plus PL-MSCs, respectively $(\mathrm{p}=0.1)$. Similar results were obtained for PMAionomycin-stimulated T cells (data not shown).

Regarding IFN- $\gamma$ production, among PMAionomycin-stimulated T cells the addition of MSCs to the culture decreased the production of this cytokine in terms of percentage and MFCs irrespective of the medium used for their expansion, although a trend toward a higher inhibitory effect was also observed for HS-MSCs (Fig. 4B): $12 \%$ of stimulated T cells produced IFN in the absence of MSC versus $5 \%$ for T cells plus HS-MSCs $(p=0.01), 7 \%$ for T cells plus FCS-MSCs $(\mathrm{p}=0.04)$, and $7 \%$ for $\mathrm{T}$ cells plus PL-MSCs ( $\mathrm{p}=0.03$ ), respectively (Fig. 4B).

The MFC of IFN- $\gamma$ was 132 in T cells stimulated in the absence of MSCs (T cells alone) versus 58, 89, and 85 in T cells plus HS-MSCs $(p=0.01)$, T cells plus FCS-MSCs $(p=0.09)$, and T cells plus PL-MSCs $(p=0.02)$, respectively. Upon comparing the effect of the different culture 

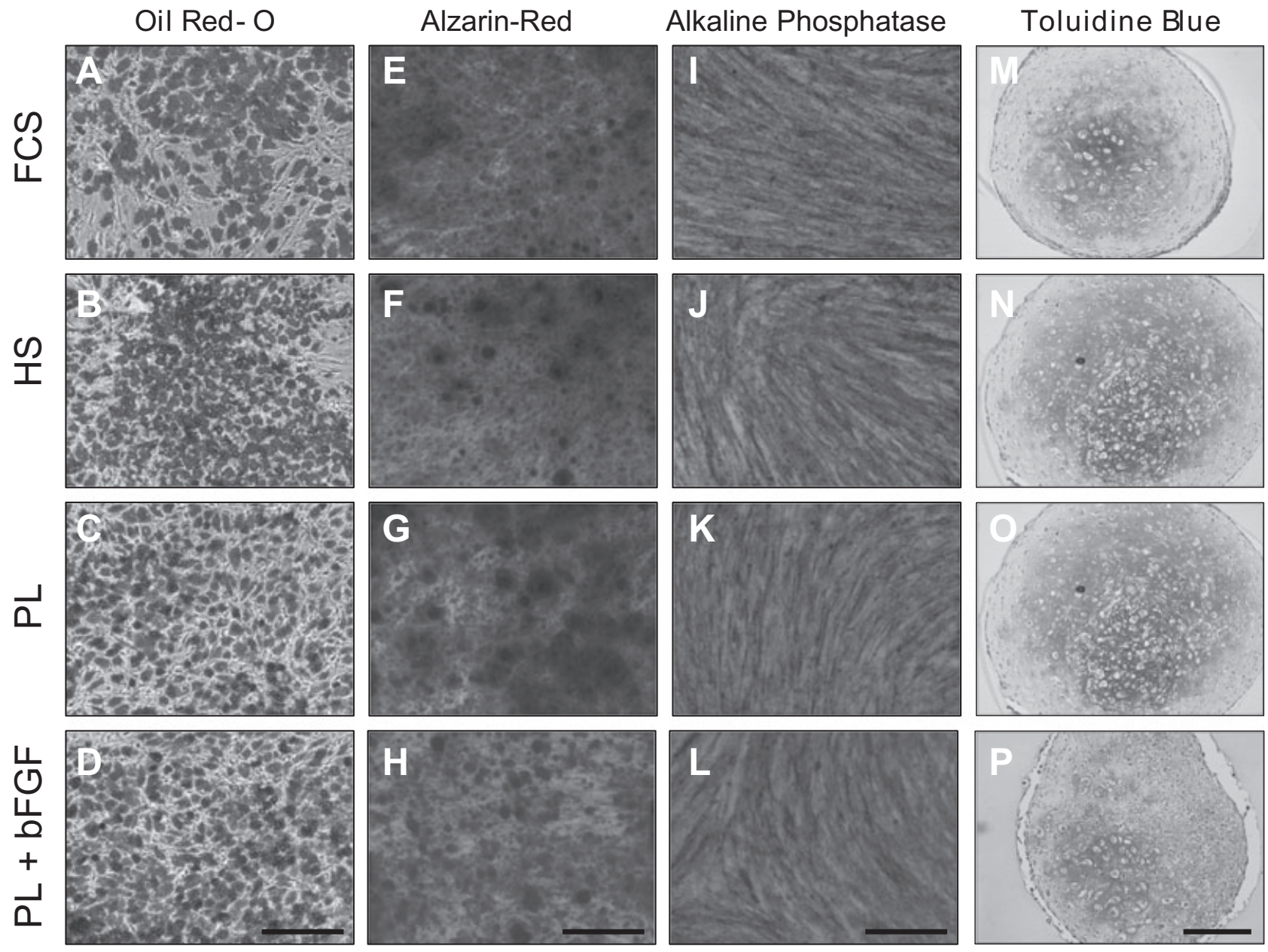

Fig. 3. Representative photographs of MSCs expanded in the presence of human serum (HS), FCS, PL, and PL with bFGF (PL + bFGF) and induced to differentiate into osteogenic, condrogenic, and adipogenic cells. (A-D) Differentiation into adipocytes is revealed by the formation of lipid droplets (stained with Oil Red-O staining). (E-L) Differentiation into osteoblasts is demonstrated by the histologic detection of calcium deposition stained with Alzarin red staining (E-H) and alkaline phosphatase activity (blue reaction product; I-L). Differentiation to condrogenic cells is demonstrated by histologic detection of extracellular matrix (metachromatic) of proteoglycan (toluidine blue staining). Magnification 10x.

media, we observed that MSCs cultured with autologous serum decreased the percentage of IFN- $\gamma$ producing $\mathrm{T}$ cells more efficiently than MSC cultured with FCS ( $p=0.03$ for percentage of positive cells and $p=0.03$ for MFCs) and similarly to PL ( $p=0.09$ for percentage of positive cells and $\mathrm{p}=0.05$ for MFCs), respectively. Similar results were obtained for anti-CD3 plus anti-CD28stimulated $\mathrm{T}$ cells (data not shown). No significant differences were observed in terms of CD25 expression among stimulated $\mathrm{T}$ cells in the absence or presence of MSCs (Fig. 4C).

\section{Proliferation assays (cell cycle)}

Proliferation assays showed a significant inhibition of cell cycle among T cells cocultured with MSCs. Accordingly, MSCs decreased the percentage of $T$ cells in phase $S$ and
G2/M irrespective of the culture medium used for their expansion (Fig. 5). Similar results were observed when we analyzed proliferation with PKH-67 staining, showing that in the presence of MSCs, T cells were in resting state after stimulation compared to proliferating state when $\mathrm{T}$ cells were not cultured in the presence of MSCs (data not shown).

\section{DISCUSSION}

In the past few years several clinical trials have been devoted to exploring the efficacy and safety of MSCbased therapy for different diseases (http://www. clinicaltrials.gov). FCS has been traditionally used to expand MSCs, but the administration of animal products to humans might cause the transmission of prions and 

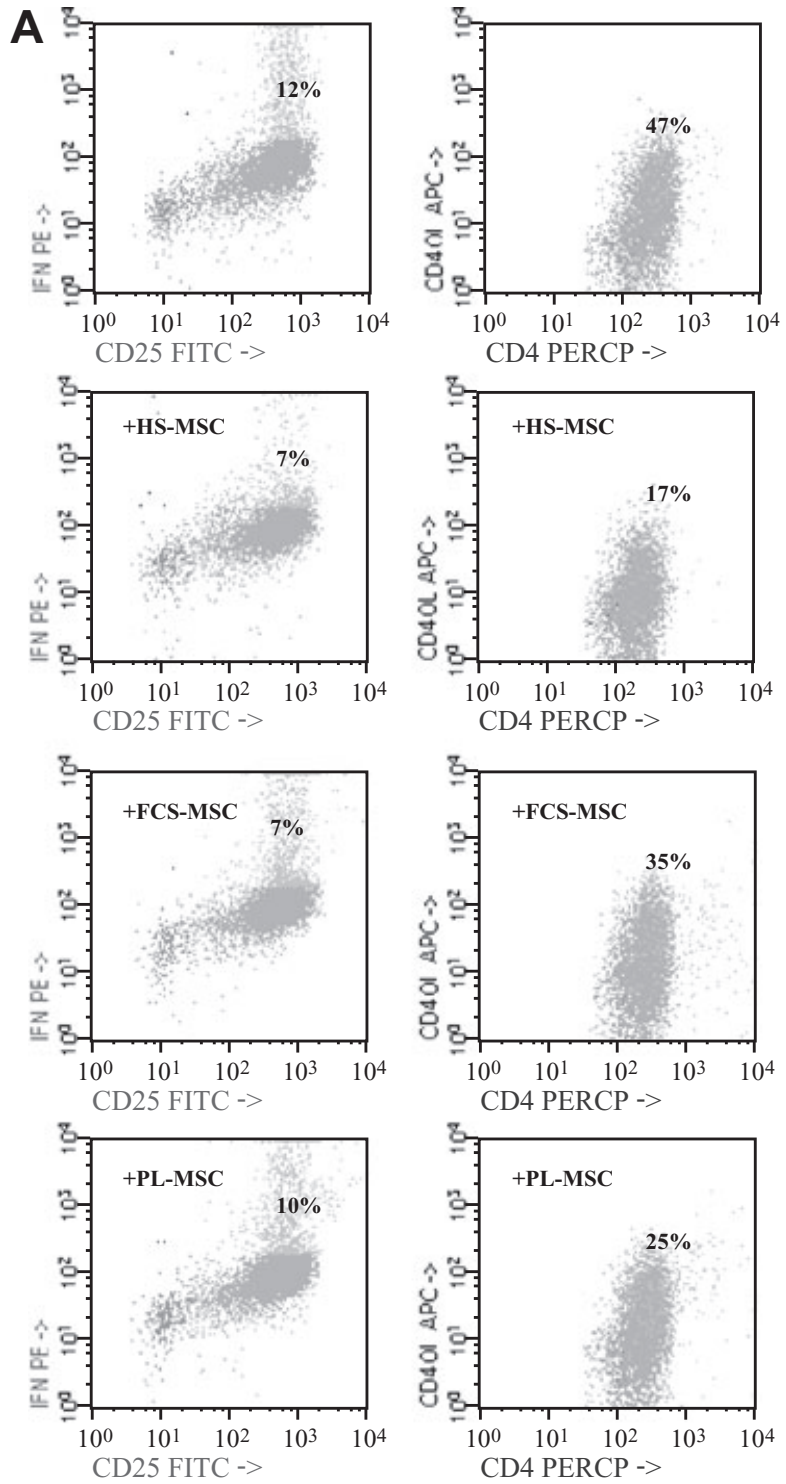
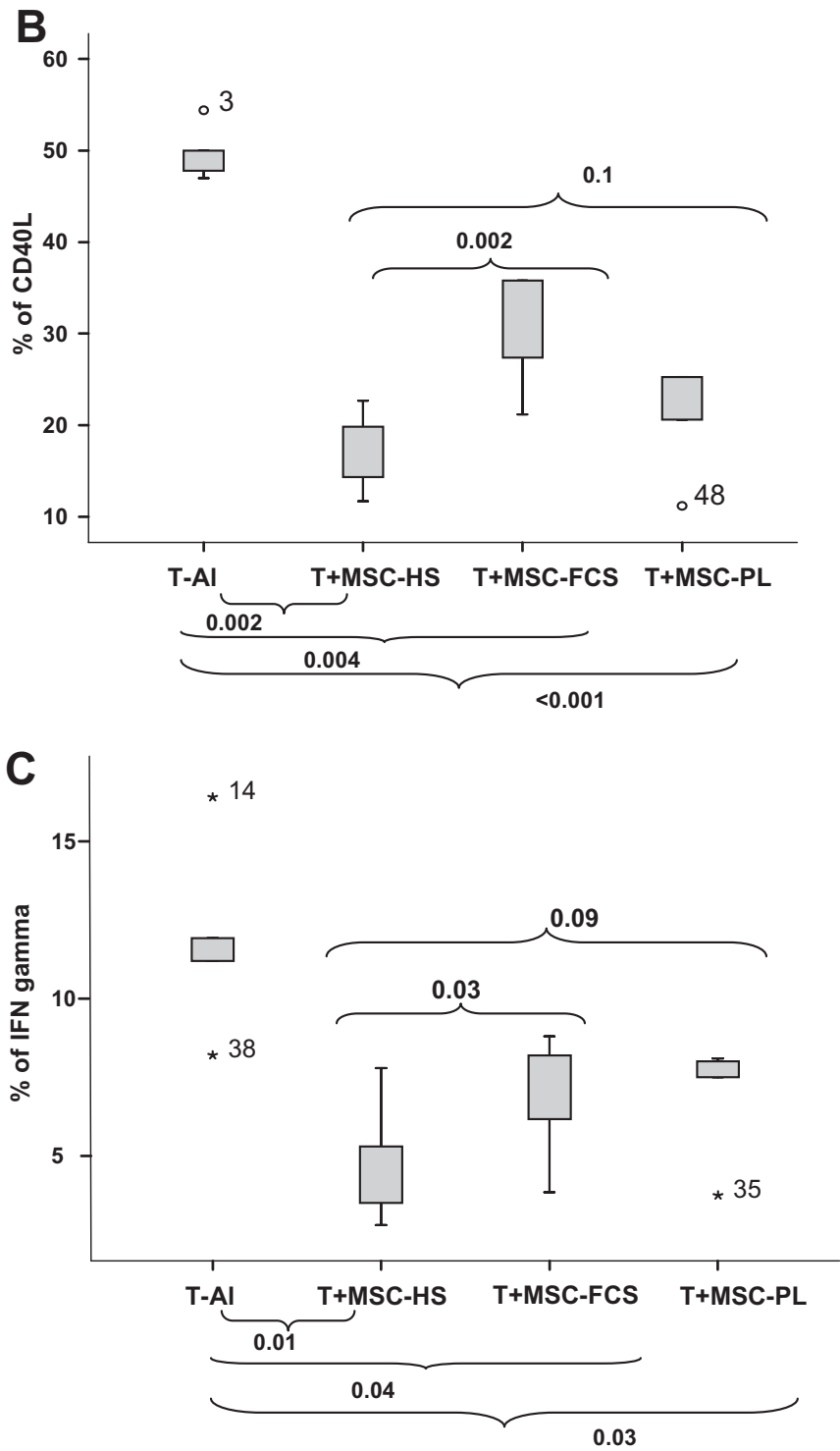

Fig. 4. Representative case on picture of five performed. (A) Dot plot showing the activation pattern in $\mathrm{T}$ cells stimulated with antiCD3/anti-CD28 plus HS-MSCs, FCS-MSCs, or PL-MSCs. (B) The expression of CD40L was significantly reduced when T cells were stimulated in the presence of MSCs: percentage of CD40L-positive T cells being 50, 17, 31, and 21\% among T lymphocytes cocultured without MSCs, with HS-MSCs, FCS-MSCs, and PL-MSCs, respectively. (C) Dot plot representing IFN- $\gamma$ production among antiCD3/anti-CD28-stimulated T cells in the absence or presence of the different types of MSCs: percentage of IFN- $\gamma$-positive T cells was 12, 5, 7, and 7\%, respectively, among T lymphocytes cocultured without MSCs, with HS-MSCs, FCS-MSCs, and PL-MSCs, respectively.

still unidentified zoonosis. In addition, when expanded in FCS containing medium, hMSCs have been implicated in anaphylactic or arthuslike immune reactions. ${ }^{19}$ Although a protocol has been described that successfully removes at least $99.99 \%$ of all FCS contamination from hMSCs expanded in $20 \% \mathrm{FCS},{ }^{20}$ the risk of disease transmission still remains. In consequence, several countries have restricted or placed warnings on the clinical use of cell therapy products prepared in the presence of FCS. In view of these considerations, different studies have focused on the identification of a serum-free medium appropriate for the growth of the large number of MSCs required for clinical application. In this regard, the use of PL or human serum as medium supplements represents interesting alternatives to FCS.

$\mathrm{PL}$ is an allogeneic clinical-grade product obtained from blood donors. Human PL enriched in PLT-rich plasma contains PLT-derived growth factor, TGF- $\beta$, 

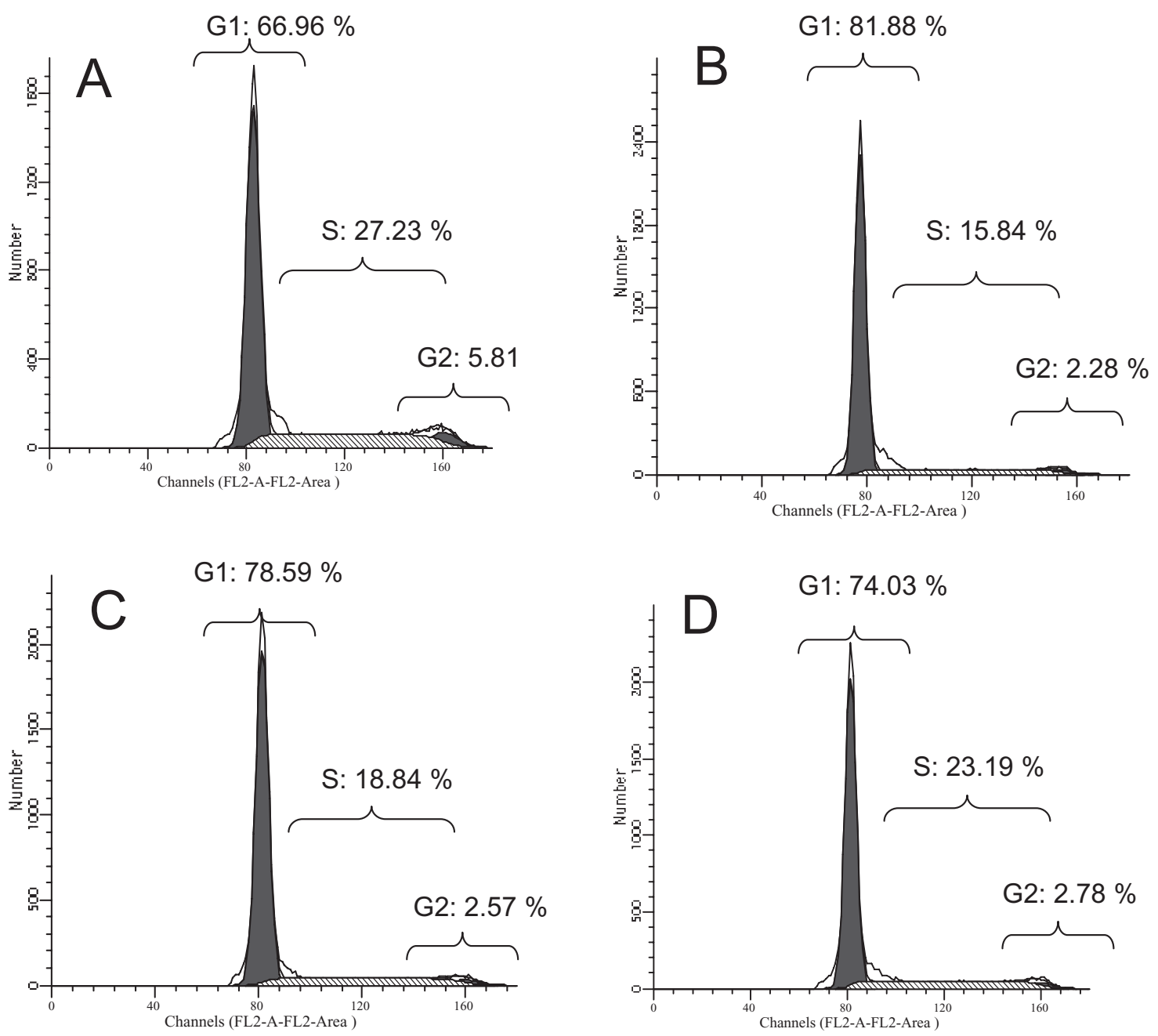

Fig. 5. Cell cycle analysis of a representative case from the five performed, assessed using PI and flow cytometry quantification in anti-CD3/anti-CD28-stimulated T cells after coculture without or with the different types of MSCs decreased the percentage of cells in phase $S$ and G2/M increasing the percentage of cells in phase G0/G1, independent of the culture medium used (A = stimulated T cells without MSCs; $\mathrm{B}=$ plus HS-MSCs; $\mathrm{C}=$ plus FCS-MSCs; and $\mathrm{D}=$ plus PL-MSCs; $\mathrm{p} \geq 0.05$ in all comparisons).

epidermal growth factor, and bFGF, which are growth factors secreted by the PLTs required for MSC culture. ${ }^{21,22}$ Although some studies have indicated that the content of growth factors varies according to PL concentration, preparation mode, and so forth ${ }^{23}$ it has also been shown that the concentration of PLT-derived growth factor- $\mathrm{AB}$, TGF- $\beta$, bFGF, and vascular endothelial growth factor is higher in PL than in many lots of FCS. ${ }^{10}$ Moreover, several studies have already shown that it is possible to expand MSCs with $\mathrm{PL}^{8,10}$ and that these MSCs cultured under laboratory-scale conditions maintain their differentiation properties and immunosuppressive activity. ${ }^{10}$

Human autologous serum would be the safest choice, since it would avoid the exposure not only to FCS but also to allogeneic products such as PL or allogeneic serum. The feasibility of culturing MSCs in medium supplemented with human serum only has been previ- ously demonstrated. ${ }^{13-15}$ Nevertheless, the use of allogeneic human serum has resulted in MSC growth arrest and death in some studies. ${ }^{20}$ Similarly, Stute and colleagues ${ }^{15}$ have reported that in media supplemented with autologous human serum, MSCs showed normal growth only early on during ex vivo culture. After 6 weeks they formed clusters and eventually died. Most clinical trials require between $0.5 \times 10^{6}$ and $5 \times 10^{6} / \mathrm{kg} \mathrm{MSCs}^{24-27}$ so the achievement of this amount is a key factor for the success of any protocol: autologous serum could not therefore be considered as a general substitute for FCS, the amount of serum available being a key limiting factor. In this regard, from one blood donation of $500 \mathrm{~mL}$, a maximum of $200 \mathrm{~mL}$ serum can be obtained, that is, supplementing medium with $10 \%$ human serum yields $2 \mathrm{~L}$ of expansion medium, which should be enough for a 2- to 3-week expansion period. We have 
previously reported a method for obtaining large amounts of autologous serum suitable for culture at a clinical scale (skeletal myoblasts), ${ }^{18}$ which would allow us to obtain the amount of autologous serum required for sufficient expansion of MSCs.

In this study, the growth, immunophenotype, differentiation potential, and immunomodulatory properties were compared between four media:

1. $10 \%$ FCS with $1 \mathrm{ng} / \mathrm{mL}$ bFGF (FCS medium);

2. $10 \%$ human serum with $1 \mathrm{ng} / \mathrm{mL}$ bFGF (HS medium);

3. $5 \%$ PL medium; and

4. PL with $1 \mathrm{ng} / \mathrm{mL}$ bFGF (PL plus bFGF medium).

Immunophenotypically, MSCs displayed a similar pattern irrespective of the medium used for culture. Accordingly, no expression of CD34 and CD45 was observed in any case and expression of CD44, CD73, and CD90 at the end of the culture (25-30 days) was similar in all four conditions. ${ }^{28}$ Similarly, the different culture conditions had the same osteogenic, adipogenic, and chondrogenic potential. These results are in accordance with those reported by Doucet and coworkers and with our previous study ${ }^{9,10}$ where we observed that MSCs expanded in the presence of PL retained their ability to differentiate into osteogenic, adipogenic, and chondrogenic lineages.

One of the most interesting properties of hMSCs for transplantation is their immunomodulating function, which has shown promising results in the clinical setting for treating GVHD. In this study, we demonstrate that MSCs expanded with human serum or PL are at least as immunosuppressive in vitro as MSCs expanded with FCS. Furthermore, our results suggest that MSCs expanded with human serum or PL induce an even more intense inhibition of CD40L expression and IFN- $\gamma$ production compared to FCS-MSCs. These results are in accordance with those previously reported by Lange and colleagues $^{29}$ and suggest that FCS may worsen the immunomodulatory capacity of MSCs. In a previous study, Bernardo and coworkers ${ }^{8}$ showed that, compared to PL-MSC, FCS-MSCs were more efficient in suppressing alloantigen-induced lymphocyte proliferation and IFN- $\gamma$ production. Perhaps the different time points (hours vs. 2 days) and methods used for analysis may explain these differences.

Finally, we found that, in terms of MSC duplication, the four media were equivalent, although the growth with autologous serum was slightly slower. In clinical practice one additional duplication would bring an important advantage: in the same time it would be possible to obtain double the number of MSCs. In conclusion, PL or autologous serum could offer an alternative to the use of FCS in MSC expansion for clinical use maintaining the same growth potential, phenotype, immunomodulatory properties, and differentiation potential.

\section{CONFLICT OF INTEREST}

The authors have declared no conflict of interest.

\section{REFERENCES}

1. Campagnoli C, Roberts IA, Kumar S, Bennett PR, Bellantuono I, Fisk NM. Identification of mesenchymal stem/ progenitor cells in human first-trimester fetal blood, liver, and bone marrow. Blood 2001;98:2396-402.

2. Erices A, Conget P, Minguell JJ. Mesenchymal progenitor cells in human umbilical cord blood. Br J Haematol 2000; 109:235-42.

3. Minguell JJ, Erices A, Conget P. Mesenchymal stem cells. Exp Biol Med (Maywood) 2001;226:507-20.

4. Colter DC, Class R, DiGirolamo CM, Prockop DJ. Rapid expansion of recycling stem cells in cultures of plasticadherent cells from human bone marrow. Proc Natl Acad Sci U S A 2000;97:3213-8.

5. Deans RJ, Moseley AB. Mesenchymal stem cells: biology and potential clinical uses. Exp Hematol 2000;28:875-84.

6. Dominici M, Hofmann TJ, Horwitz EM. Bone marrow mesenchymal cells: biological properties and clinical applications. J Biol Regul Homeost Agents 2001;15:28-37.

7. Pittenger MF, Mackay AM, Beck SC, Jaiswal RK, Douglas R, Mosca JD, Moorman MA, Simonetti DW, Craig S, Marshak DR. Multilineage potential of adult human mesenchymal stem cells. Science 1999;284:143-7.

8. Bernardo ME, Avanzini MA, Perotti C, Cometa AM, Moretta A, Lenta E, Del Fante C, Novara F, de Silvestri A, Amendola G, Zuffardi O, Maccario R, Locatelli F. Optimization of in vitro expansion of human multipotent mesenchymal stromal cells for cell-therapy approaches: further insights in the search for a fetal calf serum substitute. J Cell Physiol 2007;211:121-30.

9. Carrancio S, Lopez-Holgado N, Sanchez-Guijo FM, Villaron E, Barbado V, Tabera S, Diez-Campelo M, Blanco J, San Miguel JF, Del Canizo MC. Optimization of mesenchymal stem cell expansion procedures by cell separation and culture conditions modification. Exp Hematol 2008;36: 1014-21.

10. Doucet C, Ernou I, Zhang Y, Llense JR, Begot L, Holy X, Lataillade JJ. Platelet lysates promote mesenchymal stem cell expansion: a safety substitute for animal serum in cellbased therapy applications. J Cell Physiol 2005;205:228-36.

11. Muller I, Kordowich S, Holzwarth C, Spano C, Isensee G, Staiber A, Viebahn S, Gieseke F, Langer H, Gawaz MP, Horwitz EM, Conte P, Handgretinger R, Dominici M. Animal serum-free culture conditions for isolation and expansion of multipotent mesenchymal stromal cells from human BM. Cytotherapy 2006;8:437-44.

12. Schallmoser K, Bartmann C, Rohde E, Reinisch A, Kashofer K, Stadelmeyer E, Drexler C, Lanzer G, Linkesch W, Strunk D. Human platelet lysate can replace fetal bovine serum for clinical-scale expansion of functional mesenchymal stromal cells. Transfusion 2007;47:1436-46. 
13. Mizuno N, Shiba H, Ozeki Y, Mouri Y, Niitani M, Inui T, Hayashi H, Suzuki K, Tanaka S, Kawaguchi H, Kurihara H. Human autologous serum obtained using a completely closed bag system as a substitute for foetal calf serum in human mesenchymal stem cell cultures. Cell Biol Int 2006; 30:521-4.

14. Nimura A, Muneta T, Koga H, Mochizuki T, Suzuki K, Makino H, Umezawa A, Sekiya I. Increased proliferation of human synovial mesenchymal stem cells with autologous human serum: comparisons with bone marrow mesenchymal stem cells and with fetal bovine serum. Arthritis Rheum 2008;58:501-10.

15. Stute N, Holtz K, Bubenheim M, Lange C, Blake F, Zander AR. Autologous serum for isolation and expansion of human mesenchymal stem cells for clinical use. Exp Hematol 2004;32:1212-25.

16. Kobayashi T, Watanabe H, Yanagawa T, Tsutsumi S, Kayakabe M, Shinozaki T, Higuchi H, Takagishi K. Motility and growth of human bone-marrow mesenchymal stem cells during ex vivo expansion in autologous serum. J Bone Joint Surg Br 2005;87:1426-33.

17. Shahdadfar A, Fronsdal K, Haug T, Reinholt FP, Brinchmann JE. In vitro expansion of human mesenchymal stem cells: choice of serum is a determinant of cell proliferation differentiation, gene expression, and transcriptome stability. Stem Cells 2005;23:1357-66

18. Herreros J, Prosper F, Perez A, Gavira JJ, Garcia-Velloso MJ, Barba J, Sanchez PL, Canizo C, Rabago G, Marti-Climent JM, Hernandez M, Lopez-Holgado N, Gonzalez-Santos JM, Martin-Luengo C, Alegria E. Autologous intramyocardial injection of cultured skeletal muscle-derived stem cells in patients with non-acute myocardial infarction. Eur Heart J 2003;24:2012-20.

19. Selvaggi TA, Walker RE, Fleisher TA. Development of antibodies to fetal calf serum with arthus-like reactions in human immunodeficiency virus-infected patients given syngeneic lymphocyte infusions. Blood 1997;89:776-9.

20. Spees JL, Gregory CA, Singh H, Tucker HA, Peister A, Lynch PJ, Hsu SC, Smith J, Prockop DJ. Internalized antigens must be removed to prepare hypoimmunogenic mesenchymal stem cells for cell and gene therapy. Mol Ther 2004;9:747-56.

21. Wadhwa M, Seghatchian MJ, Lubenko A, Contreras M, Dilger P, Bird C, Thorpe R. Cytokine levels in platelet concentrates: quantitation by bioassays and immunoassays. Br J Haematol 1996;93:225-34.
22. Zimmermann R, Jakubietz R, Jakubietz M, Strasser E, Schlegel A, Wiltfang J, Eckstein R. Different preparation methods to obtain platelet components as a source of growth factors for local application. Transfusion 2001;41: 1217-24.

23. Zimmermann R, Arnold D, Strasser E, Ringwald J, Schlegel A, Wiltfang J, Eckstein R. Sample preparation technique and white cell content influence the detectable levels of growth factors in platelet concentrates. Vox Sang 2003;85: 283-9.

24. Chen SL, Fang WW, Ye F, Liu YH, Qian J, Shan SJ, Zhang JJ, Chunhua RZ, Liao LM, Lin S, Sun JP. Effect on left ventricular function of intracoronary transplantation of autologous bone marrow mesenchymal stem cell in patients with acute myocardial infarction. Am J Cardiol 2004;94:92-5.

25. Koc ON, Gerson SL, Cooper BW, Dyhouse SM, Haynesworth SE, Caplan AI, Lazarus HM. Rapid hematopoietic recovery after coinfusion of autologous-blood stem cells and culture-expanded marrow mesenchymal stem cells in advanced breast cancer patients receiving high-dose chemotherapy. J Clin Oncol 2000;18:307-16.

26. Lee ST, Jang JH, Cheong JW, Kim JS, Maemg HY, Hahn JS, Ko YW, Min YH. Treatment of high-risk acute myelogenous leukaemia by myeloablative chemoradiotherapy followed by co-infusion of $\mathrm{T}$ cell-depleted haematopoietic stem cells and culture-expanded marrow mesenchymal stem cells from a related donor with one fully mismatched human leucocyte antigen haplotype. Br J Haematol 2002;118:112831.

27. Ringden O, Uzunel M, Rasmusson I, Remberger M, Sundberg B, Lonnies H, Marschall HU, Dlugosz A, Szakos A, Hassan Z, Omazic B, Aschan J, Barkholt L, Le Blanc K. Mesenchymal stem cells for treatment of therapy-resistant graft-versus-host disease. Transplantation 2006;81:1390-7.

28. Dominici M, Le Blanc K, Mueller I, Slaper-Cortenbach I, Marini F, Krause D, Deans R, Keating A, Prockop D, Horwitz E. Minimal criteria for defining multipotent mesenchymal stromal cells. The International Society for Cellular Therapy position statement. Cytotherapy 2006;8: 315-7.

29. Lange C, Cakiroglu F, Spiess AN, Cappallo-Obermann H, Dierlamm J, Zander AR. Accelerated and safe expansion of human mesenchymal stromal cells in animal serum-free medium for transplantation and regenerative medicine. J Cell Physiol 2007;213:18-26. 